Supporting Information

\title{
Quantitative Analysis of the Reduction Kinetics Responsible for the One-Pot Synthesis of Pd-Pt Bimetallic Nanocrystals with Different Structures
}

Ming Zhou, ${ }^{\dagger}{ }^{\dagger}$ Helan Wang, ${ }^{\dagger}$ Madeline Vara,${ }^{\S}$ Zachary D. Hood, ${ }^{\S, \|}$ Ming Luo, ${ }^{\dagger}$ Tung-Han Yang, ${ }^{\dagger}$

Shixiong Bao, ${ }^{\dagger}$ Miaofang Chi, ${ }^{\|}$Peng Xiao, ${ }^{\ddagger}$ Yunhuai Zhang, ${ }^{\ddagger}$ and Younan Xia* ${ }^{\dagger}, \S$

†The Wallace H. Coulter Department of Biomedical Engineering, Georgia Institute of Technology and Emory University, Atlanta, Georgia 30332, United States

College of Chemistry and Chemical Engineering, Chongqing University, Chongqing 400044, China

${ }^{\S}$ School of Chemistry and Biochemistry, Georgia Institute of Technology, Atlanta, Georgia 30332, United States

"Center for Nanophase Materials Sciences, Oak Ridge National Laboratory, Oak Ridge, Tennessee 37831, United States

*Address correspondence to younan.xia@bme.gatech.edu 

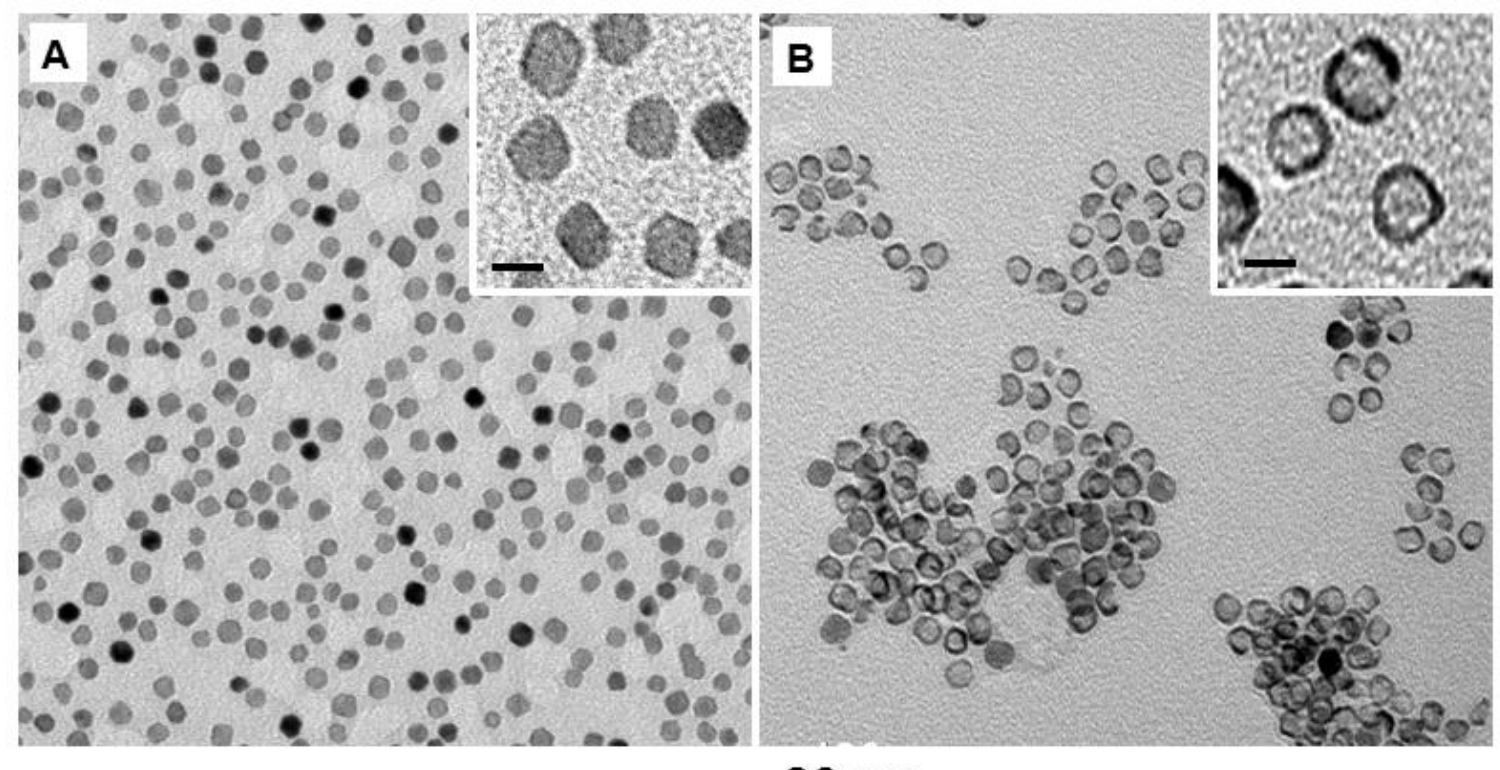

\section{$20 \mathrm{~nm}$}

Figure S1. TEM images of (A) the Pd@Pt core-shell octahedra and (B) the Pt octahedral nanocages obtained by selectively etching away the Pd cores. The average number of Pt atomic layers in the core-shell octahedra was determined to be about 2.9 based on the ICP-MS analysis. The scale bars in the insets are $5 \mathrm{~nm}$. Compared to the core-shell octahedra shown in Figure 1, the Pt shell thickness was increased from 1.9 to 2.9 atomic layers by increasing the amount of $\mathrm{Pt}(\mathrm{II})$ precursor while keeping all other conditions the same as the standard synthesis. 

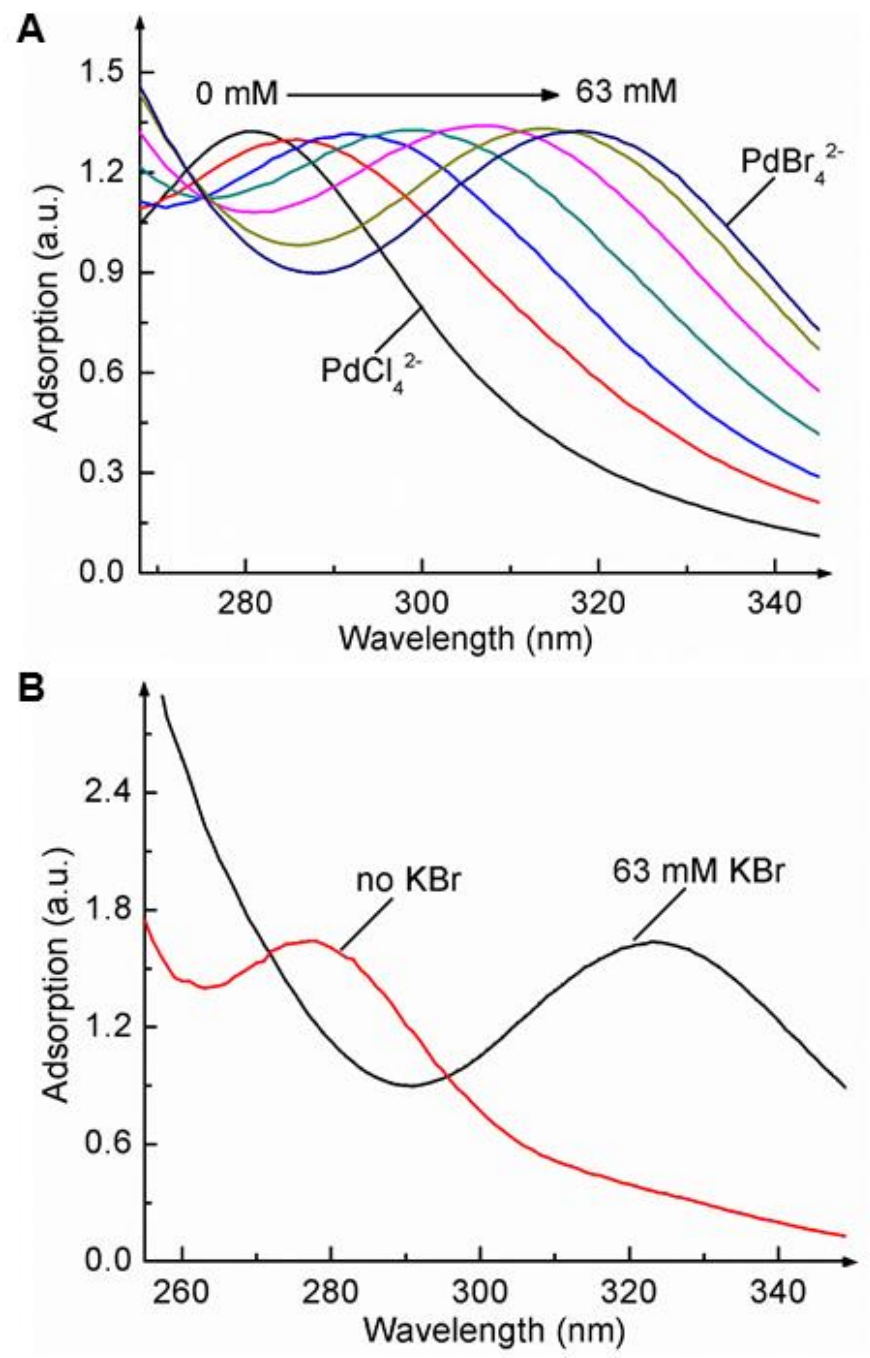

Figure S2. (A) UV-vis spectra recorded from an aqueous $\mathrm{Na}_{2} \mathrm{PdCl}_{4}$ solution $(13 \mathrm{mM})$ after the introduction of $\mathrm{KBr}$ to different concentrations labeled on the curves. (B) Comparison of the UV-vis spectra recorded from the reaction solutions containing both $\operatorname{Pd}(\mathrm{II})$ and $\operatorname{Pt}(\mathrm{II})$ precursors in the absence and presence of $63 \mathrm{mM} \mathrm{KBr}$, respectively. 

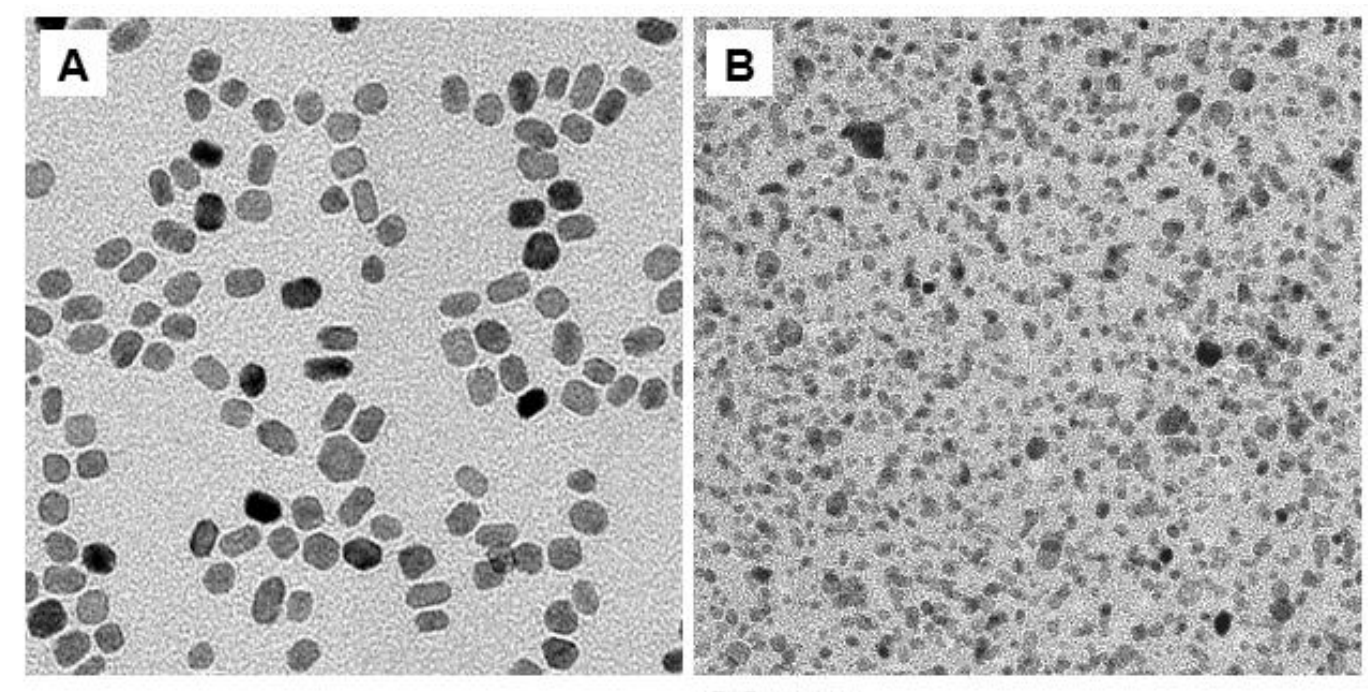

\section{$20 \mathrm{~nm}$}

Figure S3. (A) TEM image of Pd-Pt bimetallic nanocrystals obtained using a procedure similar to what was used in Figure S1, except for the use of $42 \mathrm{mM}$ in stead of $63 \mathrm{mM} \mathrm{KBr}$. (B) TEM image of the sample shown in (A) after etching with the aqueous $\mathrm{FeCl}_{3}$ solution. 


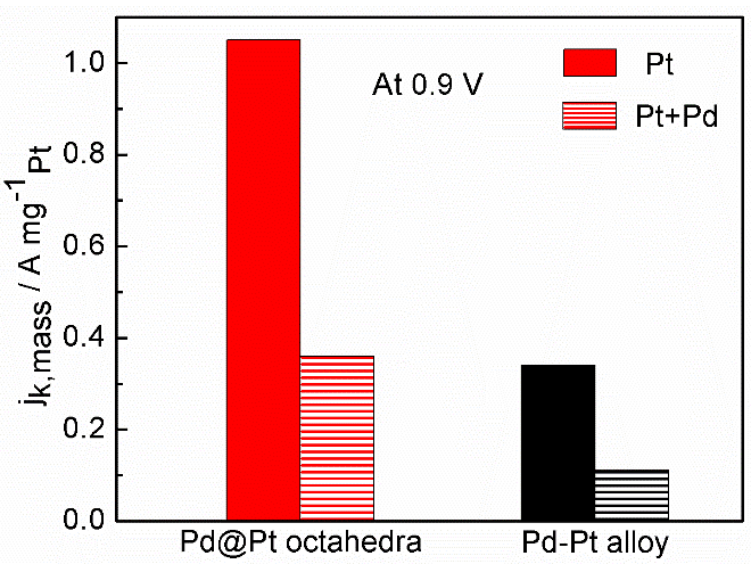

Figure S4. ORR mass activities at $0.9 \mathrm{~V}_{\mathrm{RHE}}$, which are presented as kinetic current densities $\left(j_{k}\right)$ normalized to the masses of $\mathrm{Pt}$ and $\mathrm{Pt}+\mathrm{Pd}$ of the catalysts, respectively. 


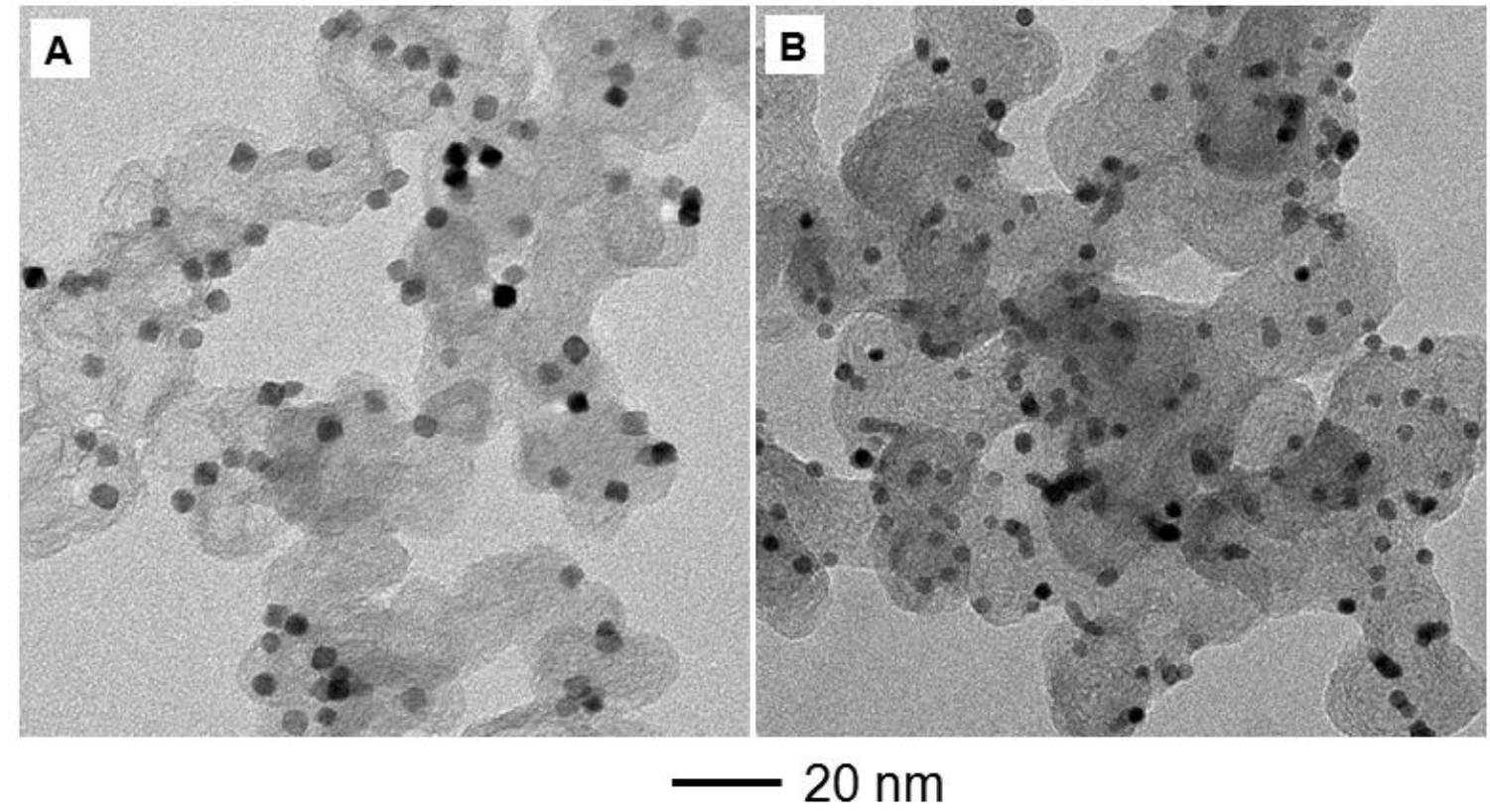

Figure S5. TEM images of the Pd@Pt/C octahedra catalyst (A) before the ORR test and (B) after 20000 cycles of accelerated durability test. 
Table S1. Comparison of the molar feeding ratios between the $\mathrm{Pd}(\mathrm{II})$ and $\mathrm{Pt}(\mathrm{II})$ precursors and the $\mathrm{Pd} / \mathrm{Pt}$ atomic ratios in the particles based on ICP-MS analyses of the Pd@Pt core-shell octahedra and $\mathrm{Pd}-\mathrm{Pt}$ alloy nanocubes.

\begin{tabular}{|c|c|c|}
\hline & $\begin{array}{c}\text { Pd(II)/Pt(II) feeding } \\
\text { molar ratio }\end{array}$ & $\begin{array}{c}\text { Pd/Pt atomic ratio of the particles from } \\
\text { ICP-MS analysis }\end{array}$ \\
\hline core-shell octahedra & 3.7 & 3.73 \\
\hline alloy nanocubes & 3.7 & 4.26 \\
\hline
\end{tabular}

